\title{
Is screening for Chlamydia trachomatis infection cost effective?
}

\section{Symposium}

\author{
Jorma Paavonen
}

Chlamydial infections are the most prevalent bacterial sexually transmitted infections recognised throughout the world. According to the WHO, 50-70 million chlamydial infections are detected annually worldwide. ${ }^{1}$ In most developed countries, sexually transmitted chlamydial infections are still strikingly common particularly among adolescents, and 10-20 times more common than gonococcal infections. ${ }^{1}$ In our recent study, the prevalence of Chlamydia trachomatis infection was $5.6 \%$ among asymptomatic women attending a family planning clinic and a student health clinic. ${ }^{2}$ Chlamydial infections cause major medical, social, and economic problems. Sequelae of $C$ trachomatis infection are extremely costly to the healthcare system, and include pelvic inflammatory disease (PID), ectopic pregnancy, tubal factor infertility (TFI), epididymitis, proctitis, and arthritis. Chlamydial infections, like STDs in general, are primarily a woman's healthcare issue since the manifestations and consequences in women are more damaging to the reproductive tract than in men. Expensive medical high technology, such as in vitro fertilisation (IVF), has largely emerged because of reproductive tract damage caused by sexually transmitted chlamydial infections. There is a strong link between past chlamydial infection and TFI or ectopic pregnancy. Emerging evidence suggests that $C$ trachomatis infection is a significant risk factor for other adverse pregnancy outcomes-that is, preterm delivery and spontaneous abortion. ${ }^{3}$ Recent studies also suggest that $C$ trachomatis infection is an independent risk factor for the development of cervical neoplasia..$^{3-6}$ Since chlamydial infections are usually asymptomatic, the key to the prevention of chlamydial infections and their sequelae is screening using a high performance diagnostic test. Screening based on first void urine (FVU) testing by gene amplification techniques, in combination with single dose therapy with azithromycin may have a major impact on the prevention and control of asymptomatic chlamydial infections. Disease prevention can be primary, secondary, or tertiary.

Tertiary prevention of acute and chronic chlamydial infections of the upper genital tract has largely failed because substantial tubal damage has already occurred by the time symptoms develop or the patient presents with infertility or ectopic pregnancy. Primary prevention involves preventing both exposure to and acquisition of chlamydial infection through lifestyle counselling and health education. Clearly, more emphasis should be directed to primary prevention by implementing health education programmes among ado- lescents. Secondary prevention by universal screening, however, is likely to play the most critical role in the prevention of PID and long term sequelae, although this still needs to be proved in randomised controlled intervention trials. $^{7}$ Secondary prevention means early detection of subclinical disease by screening or case finding in order to prevent lower genital tract infection from ascending to the upper genital tract. Chlamydial infection fills the general prerequisites for disease prevention by screening since chlamydial infections are highly prevalent, are associated with significant morbidity, can be diagnosed, and are treatable.

Cost analyses are becoming more common among trials which compare therapeutic or procedural healthcare interventions. ${ }^{8-12}$ The most widely known form of economic evaluation is cost-benefit analysis. ${ }^{13}$ It is restricted to those forms of evaluation that are used to place a monetary value on benefits and outcomes. This makes cost-benefit analysis the most comprehensive and theoretically sound form of economic evaluation. On the other hand, in cost effectiveness analysis the outcomes are not measured in monetary units, but in clinical units such as cases of PID or TFI. ${ }^{14}$ Recent studies have addressed the cost effectiveness of identifying and treating $C$ trachomatis infections in asymptomatic women. ${ }^{1516}$ Genc and Mardh ${ }^{15}$ showed that when the prevalence of chlamydial infection exceeded $6 \%$, screening of women with DNA amplification assay of endocervical swabs (and treatment of positive women with a single oral dose of azithromycin) was the most cost effective intervention strategy. If the prevalence was even higher, screening with enzyme immunoassay of cervical specimens also generated savings and improved the cure rates compared with a "no screening" situation. Diagnosis of $C$ trachomatis by tissue cell culture of cervical swabs was cost effective only when the prevalence of infection was greater than $14 \%$. Most of the savings generated by the screening strategy were attributable to prevention of complications and sequelae of chlamydial infection in women. However, the study anticipated that only women who have clinical symptoms of PID are at risk for infertility, ectopic pregnancy, or chronic pelvic pain. Hence, subclinical or silent upper genital tract infections caused by $C$ trachomatis were not considered. We recently developed a computer based decision tree model in order to conduct a more thorough cost-benefit analysis of screening versus no screening situation, based on testing of first void urine specimens with PCR among women. ${ }^{17}$ The decision tree

\footnotetext{
Obstetrics and Gynecology, University Hospital Finland J Paavonen 4 February 1997
} 
model can be used in a wide range of socioeconomic analyses. ${ }^{18}$ It is a quantitative technique which measures the overall performance of a specific healthcare intervention, such as a new diagnostic test. We also considered silent or subclinical chlamydial infections in order to improve the reliability of the results. Compared with conventional diagnostic methods, such as cell culture or enzyme immunoassays, PCR and LCR allow testing of FVU samples in both women and men with a high level of sensitivity and specificity. ${ }^{19-21}$ According to the model, in the no screening situation systematic FVU screening for $C$ trachomatis was not performed, and only symptomatic women were tested using conventional fluorescent antibody (FA) confirmed enzyme immunoassay on cervical swabs (MicroTrak Chlamydia EIA, Syva Co, Palo Alto, CA, USA). $C$ trachomatis positive women and their current partners were contacted and treated systematically with a single dose of azithromycin $1 \mathrm{~g}$. In the screening situation a FVU screening policy targeted to women of childbearing age was applied. All screened individuals were tested using $C$ trachomatis PCR assay (Amplicor, Roche Diagnostic Systems, Basle, Switzerland) on FVU specimens. Only direct costs due to chlamydial infection were included. The costs per capita of the screening situation and the no screening situation were calculated. The cost of the screening strategy was $16 \%$ less per capita if the participation rate in the screening programme was at least $75 \%$. When the sensitivity of the screening test was $90 \%$, the threshold value for the prevalence of $C$ trachomatis infection was as low as $3 \cdot 2 \%$ (that is, screening in a low prevalence population would still be cost effective). The cost savings increased with increasing prevalence, and when the prevalence approached $10 \%$ (for example, in a high risk population) the net savings were approximately $30 \%$ per capita. Sensitivity analyses showed that in addition to lower costs, the screening situation also produced considerable health benefits compared with the no screening situation-that is, the proportion of cured patients increased by about $85 \%$ and about $50 \%$ less suffered from long term complications.

There is clear evidence that systematic screening of asymptomatic populations decreases the incidence of $C$ trachomatis infections. This has been documented both in nationwide screening programmes ${ }^{22}$ and in screening programmes performed in other defined populations in which the screening activity has remained stable. ${ }^{23}$ Furthermore, recent randomised clinical trial have shown that intervention with selective screening of chlamydial infections effectively reduces the incidence of PID. ${ }^{7}$ It still remains to be seen whether such intervention will also have a significant effect on the rate of long term sequelae of chlamydial infections.

Since $C$ trachomatis is the major cause of female genital tract infections and infertility and adverse pregnancy outcome, prevention and control of these infections and their sequelae will have a major impact on the reproductive health of women. Further socioeconomic studies linking the cost of secondary prevention of $C$ trachomatis infections and the cost of infertility or adverse pregnancy out- $\Phi$ come are warranted.

1 Piot $P$, Islam MQ. Sexually transmitted diseases in the 1990s. Global epidemiology and challenges for control. Sex Transm Dis 1994;21:S7-S13.

2 Paukku M, Puolakkainen $M$, Apter $D$, Hirvonen $S$, $\mathbb{Q}$ Paavonen J. First void urine testing for Chlamydia trachomatis by polymerase chain reaction in asymptomatic women. Sex Transm Dis (in press).

3 Witkin SS. Immune pathogenesis of asymptomatic $\vec{\sigma}$ Chlamydia trachomatis infections in the female genital Chlamydia trachomatis infections in the femal
tract. Infect Dis Obstet Gynecol 1995;3:169-74.

4 Hakama M, Lehtinen M, Knekt P, Aromaa A, Leinikki P, Miettinen A, et al. Serum antibodies and subsequent cer- $\mathbb{D}$ vical neoplasms: a prospective study with 12 years followup. Am $\mathcal{F}$ Epidemiol 1993;137:166-70.

5 Lehtinen M, Dillner J, Knekt P, Luostarinen T, Aromaa A, Kimbauer $R$, et al. Serologically diagnosed infection with $\overrightarrow{0}$ human papillomavirus type 16 and risk for subsequent development of cervical carcinoma: nested case-control $\vec{\omega}$ study. $B M \mathcal{F}$ 1996;312:537-9.

6 Paavonen J. Chlamydia and cancer. Proceedings of the $\dot{\omega}$ Third Meeting of the European Society for Chlamydia Research, Chantilly, France 1996:167.

7 Scholes D, Stergachis A, Heidrich FE, Andrilla H, Holmes $\mathrm{KK}$, Stamm WE, et al. Prevention of pelvic inflammatory disease by screening for cervical chlamydial infection. $N \overrightarrow{\mathrm{O}}$

8 Genç M, Ruusuvaara L, Mårdh P-A. An economic evalua- 음 tion of screening for Chlamydia trachomatis in adolescent males. $\mathcal{F A M A}$ 1993;270:2057-64

9 Neumann PJ, Gharib SD, Weinstein MC. The cost of a successful delivery with in vitro fertilisation. $N$ Engl $\mathcal{f}$ 을 Med 1994;331:239-43.

10 Lappalainen $M$, Sintonen $H$, Koskiniemi $M$, Hedman $K, \vec{C}$ Hiilesmaa V, Ammala P, et al. Cost-benefit analysis of screening for toxoplasmosis during pregnancy. Scand $\mathcal{F}$ Infect Dis 1995;27:265-72.

11 Rosenberg MJ, Waugh MS. Doxycycline or ofloxacin for outpatient chlamydial pelvic inflammatory disease? A cost-benefit and cost-effectiveness analysis. Infect Dis Obstet Gynecol 1995;3:12-21.

12 Goldfarb JM, Austin C, Lisbona H, Peskin B, Clapp M. D Cost-effectiveness of in vitro fertilisation. Obstet Gynecol 1996;87:18-21.

13 Robinson R. Cost-benefit analysis. BMF 1993;307:924-6.

14 Robinson R. Economic evaluation and health care. What does it mean? $B M F$ 1993;307:670-3.

15 Genç M, Mårdh P-A. A cost-effectiveness analysis of screening and treatment for Chlamydia trachomatis infection in asymptomatic women. Ann Intern Med 1996; $\stackrel{\infty}{=}$ 124:1-7.

16 Marrazzo JM, Celum CL, Fine D, DeLisle S, Mosure DJ, Handsfield $\mathrm{HH}$. Cost-effectiveness of selective vs universal screening for Chlamydia trachomatis infection in 0 women attending family planning and STD clinics. In: women attending family planning and STD clinics. In: Ridgway GL, et al, eds. Chlamydial infections. Bologna: Societa Editrice Esculapio, 1994:63-6.

17 Paavonen J, Puolakkainen M, Paukku M, Sintonen H. Cost-benefit analysis of screening for cervical Chlamydia infection in low prevalence population. Proceedings of $N$ the Third Meeting of the European Society for Chlamydia Research, Chantilly, France 1996:254.

18 Sackett DL, Haynes RB, Guyatt GH. Clinical epidemiology. $A$ 요 basic science for clinical medicine. Toronto: Little, Brown, $\omega$ 1991

19 Quinn TC, Welsh L, Lentz A, Crotchfelt K, Zenilman J, Newhall J, et al. Diagnosis of Chlamydia trachomatis infection in urine les by Amplicor polymerase chain reaction in women and men attending sexually transmitted disease clinics. F Clin Microbiol 1996;34:1401-6.

20 Lee HH, Chernesky MA, Schachter J, Burczak JD, Andrews WW, Muldoon S, et al. Diagnosis of Chlamydia trachomatis genitourinary infection in women $\mathbb{D}$ by ligase chain reaction assay of urine. Lancet 1995;345: $\frac{\mathcal{D}}{\mathbb{Q}}$ $213-6$.

21 Schachter J, Moncada J, Whidden R, Shaw H, Bolan G, Burczak JD, et al. Noninvasive tests for diagnosis of Chlamydia trachomatis infection: application of ligase 8 chain reaction to first-catch urine specimens of women. $\mathcal{F}$ Infect Dis 1995;172:1411-4.

22 Ripa T, Bauman H-D. Public health care against $C$ trachomatis, a case to win. The Swedish experience and model calculations. Eleventh Meeting on the International Society for STD Research, New Orleans, Louisiana, 27-30 August 1995. Abstract no 254.

23 Apter D. Incidence of chlamydia genital infections in a Finnish student population. (Abstract 59.) Congress of the European Union for School and University Health the European Union for School
and Medicine, York, UK, 1995. 